\title{
New insights in the assessment of left ventricular dyssynchrony: Laying the foundations for phase analysis by cardiac SPECT
}

\author{
Aju P. Pazhenkottil, MD, ${ }^{\mathrm{a}, \mathrm{b}}$ and Dominik C. Benz, $\mathrm{MD}^{\mathrm{a}}$ \\ a Cardiac Imaging, Department of Nuclear Medicine, University Hospital Zurich, Zurich, \\ Switzerland \\ b Department of Cardiology, University Hospital Zurich, Zurich, Switzerland
}

Received Dec 29, 2018; accepted Dec 31, 2018

doi: 10.1007/s12350-019-01622-1

\section{See related article, pp. 2273-2279}

Chronic heart failure still poses major challenges for the patient, the healthcare system, and the treating physician despite the fact that novel pharmacological (e.g., angiotensin-neprilysin inhibitor) and interventional treatments (e.g., cardiac resynchronization therapy or transcatheter mitral-valve repair) battle the high morbidity and mortality with great promise. ${ }^{1-3}$ Therefore, careful and comprehensive analysis of these patients is needed to help the treating physician making the right decision on the optimal allocation of the available resources.

One of these resources is cardiac resynchronization therapy (CRT). Since intraventricular dyssynchrony may depress cardiac contractility further in some patients with chronic heart failure, the CRT device coordinates the contraction of the left ventricle, demonstrating improved quality of life as well as outcome. ${ }^{1,4}$ Consequently, current guidelines recommend CRT in symptomatic patients with left ventricular ejection fraction $(\mathrm{LVEF}) \leq 35 \%$ and $\mathrm{QRS}$ duration $\geq 130$ milliseconds (with left bundle branch block morphology). ${ }^{5}$ However, a substantial number of patients who meet

Funding The University Hospital Zurich holds a research agreement with GE Healthcare.

Reprint requests: Aju P. Pazhenkottil, Cardiac Imaging, Department of Nuclear Medicine, University Hospital Zurich, Ramistrasse 100, 8091 Zurich, Switzerland; aju.pazhenkottil@usz.ch

J Nucl Cardiol 2020;27:2280-2.

$1071-3581 / \$ 34.00$

Copyright (C) 2019 American Society of Nuclear Cardiology. guideline indication fail to benefit from CRT. ${ }^{4}$ Therefore, better tools to identify candidates for CRT are needed in order to optimize resource allocation.

Cardiac single photon emission computed tomography (SPECT) myocardial perfusion imaging (MPI) may be such a tool. It provides valuable information on two major pathophysiological determinants of CRT response. On one hand, cardiac SPECT MPI detects the extent and localization of LV scar tissue. It has been shown that the extent of scar tissue and viable myocardium is directly related to the response to CRT. ${ }^{6}$ On the other hand, LV mechanical dyssynchrony can be evaluated in gated cardiac SPECT MPI by phase analysis. Thereby, the onset of mechanical contraction is measured at multiple points across the LV myocardium and its distribution is visualized by either a polar map or a histogram. With increasing mechanical dyssynchrony, the phase standard deviation and the bandwidth of the histogram are widened. Most importantly, CRT response is associated with larger histogram bandwidth and phase standard deviation. ${ }^{7}$ In addition, LV dyssynchrony assessed by phase analysis from cardiac SPECT MPI could predict major adverse cardiac events independent of other known predictors such as perfusion defects or decreased LV ejection fraction. ${ }^{8}$ Despite its promising evidence and clinical relevance, these parameters of imaging-derived LV dyssynchrony have been adopted restrainedly. One explanation may originate in its terminology, and the fact that the mechanical dyssynchrony in cardiac SPECT MPI is given in degrees of cardiac cycle while cardiologist are experienced readers of electrocardiograms (ECG) and, thus, more familiar with milliseconds.

In the current issue of the Journal, Barron et al. investigated the influence of degrees and time of cardiac 
cycle in a retrospective analysis of 399 patients with normal perfusion and function on gated post-stress cardiac SPECT images. Using these images, phase analysis-in degrees and in milliseconds-was performed across the LV myocardium and distribution of mean phase (i.e., the onset of mechanical contraction within the cardiac cycle) was visualized on a polar map and a phase histogram. While standard deviation and bandwidth were not affected by heart rate when expressed in degrees of the cardiac cycle, there was a significant correlation between heart rate and the two values when phase analysis was expressed in milliseconds. Among the latter, a rising heart rate led to a decreasing bandwidth and standard deviation. The authors concluded that although less intuitive to cardiologists, phase analysis is more robust when measured in degrees than in milliseconds.

The authors should be congratulated for this elegantly and properly performed study highlighting the necessity to measure parameters of mechanical dyssynchrony (i.e., bandwidth and standard deviation) in degrees of the cardiac cycle rather than in milliseconds. The study, furthermore, offers valuable insights into the physiological response of mechanical dyssynchrony to changes in heart rate. Nevertheless, as for every study, there are certain weaknesses and limitations that deserve closer attention. First, the study is limited to a homogeneous population with normal perfusion and function, and, as recognized by the authors, did not include "the patients that phase analysis will be clinically applied to." The present findings need to be confirmed in a population with reduced LVEF and electrical dyssynchrony. Second, mechanical dyssynchrony was assessed in post-stress instead of rest gated SPECT images. In view of the long interval between stress testing and image acquisition (i.e., 30-60 minute), however, relevant confounding is unlikely. ${ }^{9}$ Last but not least, the problematic influence of heart rate on timing values in milliseconds had been recognized over a decade ago and, although clinically less appealing, it was considered more appropriate to express all timing values in degrees or percentages of the averaged cardiac cycle duration. ${ }^{7,10}$ In line with those studies, the current study specifies the correct way to measure mechanical dyssynchrony in cardiac SPECT MPI.

Considering its high reproducibility, even in comparison to $\mathrm{ECG},{ }^{11,12}$ the present study lays the foundation for phase analysis by cardiac SPECT MPI in clinical routine-a technique complementary to perfusion and viability assessment without any extra costs or risks. ${ }^{13}$ In view of the emerging evidence that $\mathrm{LV}$ dyssynchrony can be accurately assessed by phase analysis from cardiac SPECT MPI and may predict CRT response, it brings new hope for the challenges that physicians face in the management of patients with chronic heart failure. ${ }^{14,15}$

\section{Disclosure}

Dr. Benz reports a research grant from Theodor und Ida Herzog-Egli-Foundation. A.P.P. report that he has no relationships relevant to the contents of this editorial to disclose.

\section{References}

1. Cleland JG, Daubert JC, Erdmann E, Freemantle N, Gras D, Kappenberger L, et al. The effect of cardiac resynchronization on morbidity and mortality in heart failure. $\mathrm{N}$ Engl $\mathrm{J}$ Med. 2005;352:1539-49.

2. McMurray JJ, Packer M, Desai AS, Gong J, Lefkowitz MP, Rizkala AR, et al. Angiotensin-neprilysin inhibition versus enalapril in heart failure. N Engl J Med. 2014;371:993-1004.

3. Stone GW, Lindenfeld J, Abraham WT, Kar S, Lim DS, Mishell JM, et al. Transcatheter mitral-valve repair in patients with heart failure. N Engl J Med. 2018;379(24):2307-18.

4. Abraham WT, Fisher WG, Smith AL, Delurgio DB, Leon AR, Loh $\mathrm{E}$, et al. Cardiac resynchronization in chronic heart failure. $\mathrm{N}$ Engl J Med. 2002;346:1845-53.

5. Ponikowski P, Voors AA, Anker SD, Bueno H, Cleland JG, Coats AJ, et al. 2016 ESC Guidelines for the diagnosis and treatment of acute and chronic heart failure: The Task Force for the diagnosis and treatment of acute and chronic heart failure of the European Society of Cardiology (ESC)Developed with the special contribution of the Heart Failure Association (HFA) of the ESC. Eur Heart J. 2016;37:2129-200.

6. Ypenburg C, Schalij MJ, Bleeker GB, Steendijk P, Boersma E, Dibbets-Schneider P, et al. Impact of viability and scar tissue on response to cardiac resynchronization therapy in ischaemic heart failure patients. Eur Heart J. 2007;28:33-41.

7. Boogers MM, Van Kriekinge SD, Henneman MM, Ypenburg C, Van Bommel RJ, Boersma E, et al. Quantitative gated SPECTderived phase analysis on gated myocardial perfusion SPECT detects left ventricular dyssynchrony and predicts response to cardiac resynchronization therapy. J Nucl Med. 2009;50: $718-25$.

8. Pazhenkottil AP, Buechel RR, Husmann L, Nkoulou RN, Wolfrum M, Ghadri JR, et al. Long-term prognostic value of left ventricular dyssynchrony assessment by phase analysis from myocardial perfusion imaging. Heart. 2011;97:33-7.

9. Benz DC, Gaemperli O. The right timing for post-ischemic stunning. J Nucl Cardiol. 2017;24:1302-4.

10. Kapetanakis S, Kearney MT, Siva A, Gall N, Cooklin M, Monaghan MJ. Real-time three-dimensional echocardiography: A novel technique to quantify global left ventricular mechanical dyssynchrony. Circulation. 2005;112:992-1000.

11. Trimble MA, Velazquez EJ, Adams GL, Honeycutt EF, Pagnanelli RA, Barnhart HX, et al. Repeatability and reproducibility of phase analysis of gated single-photon emission computed tomography myocardial perfusion imaging used to quantify cardiac dyssynchrony. Nucl Med Commun. 2008;29:374-81.

12. Vancura V, Wichterle D, Ulc I, Šmíd J, Brabec M, Zárybnická M, et al. The variability of automated QRS duration measurement. Europace. 2017;19:636-43.

13. Pazhenkottil AP, Buechel RR, Nkoulou R, Ghadri JR, Herzog BA, Husmann L, et al. Left ventricular dyssynchrony assessment by 
phase analysis from gated PET-FDG scans. J Nucl Cardiol. 2011;18:920-5.

14. Henneman MM, Chen J, Ypenburg C, Dibbets P, Bleeker GB, Boersma E, et al. Phase analysis of gated myocardial perfusion single-photon emission computed tomography compared with tissue Doppler imaging for the assessment of left ventricular dyssynchrony. J Am Coll Cardiol. 2007;49:1708-14.
15. Benz DC, Pazhenkottil AP. Cardiac resynchronization therapy in chronic heart failure: Effect on right ventricular function. J Nucl Cardiol. 2017. https://doi.org/10.1007/s12350-017-0953-5.

Publisher's Note Springer Nature remains neutral with regard to jurisdictional claims in published maps and institutional affiliations. 